\title{
Non-metric variation in red vole populations within the East-Ural Radioactive Track (EURT) zone
}

\author{
Alexey G. VASILYEV and Irina A. VASILYEVA
}

\begin{abstract}
Vasilyev A. G. and Vasilyeva I. A. 1995. Non-metric variation in red vole populations within the East-Ural Radioactive Track (EURT) zone. [In: Ecological genetics in mammals II. G. B. Hartl and J. Markowski, eds]. Acta Theriologica, Suppl. 3: 55-64.

Ecological monitoring of red vole Clethrionomys rutilus (Pallas, 1778) populations, carried out for two years (1992-1993) in the Sverdlovsk region near Kamensk-Ural'ski, revealed an increase of morphological diversity in terms of non-metric skull traits along the axis of the East-Ural Radioactive Track (EURT). In the population affected by radioactive contamination, frequencies of non-metric skull traits deviated significantly from those in two control populations located beyond the EURT boundaries. The deviations were not related to particular environmental factors varying among the years of our study, which implied a genetic basis of non-metric differentiation. We suggest that the observed increase of phenotypic malformations within the EURT zone has been caused by the permanent impact of low doses of radioactive contamination, leading to an accumulation of minor mutations and to disurbances in regular ontogenetic development of the red vole.
\end{abstract}

Institute of Plant and Animal Ecology, Ural Division RAS, 620219 Ekaterinburg, 8 Marta str. 202, Russia

Key words: Clethrionomys rutilus, non-metric traits, radiactive contamination, Russia

\section{Introduction}

Investigating the genetic and morphogenetic consequences of ecosystem contamination by radionucleids after the Chernobyl accident is one of the most important research targets of ecological genetics in Russia. Prior to Chernobyl, in 1957, there was a serious accident (about 2 million c) in the South Urals near Kyshtym which resulted in the formation of the so called East-Ural Radioactive Track (EURT). Studies carried out in the northern part of the EURT, the Sverdlovsk region, have shown relatively low levels of radioactive contamination of the territory as a whole. However, in the most contaminated areas located along the axis of the track, the intensity of contamination by ${ }^{137} \mathrm{Cs}$ was 1.7 to 3.2 times higher, and that by ${ }^{90} \mathrm{Sr}$ was 7 to 40 times higher than in control areas (Yushkov et al. 1993). In 1992 and 1993 various authors examined populations of the red vole Clethrionomys rutilus (Pallas, 1778), inhabiting areas that differed as to the degree of radioactive contamination both within and outside the EURT zone. This species was chosen as model for monitoring due to its high population density and 
its occurrence also in forest ecosystems most contaminated by radionucleids. Populations of the red vole have been directly exposed to the influence of radioactive contamination on large territories for approximately 100 generations. According to Il'enko and Krapivko (1993), red vole populations subjected to a permanent irradiation at low doses have probably experienced considerable changes in their genetic structure. Furthermore, it is known that a high concentration of ${ }^{90} \mathrm{Sr}$ in the animal skeleton disturbs the process of osteogenesis (Il'enko 1974), which leads to various deformations of the skeleton, to losses of bone fragments, and to changes in the expression of non-metric skeletal traits.

Inter-individual differentiation and fluctuating asymmetry in minor morphological characters (non-metric skeletal traits) have been used in a number of species to study the influence of various environmental factors, including radioactive contamination, on regular ontogenetic development (eg Timofeeff-Ressovsky et al. 1975, Il'enko 1974, Palmer and Strobeck 1986, Yablokov 1986, Zakharov 1987, Clarke 1992, Parsons 1992, Zakharov and Clarke 1993). It was the aim of the present investigation to evaluate the effects of permanent exposure to low radiation on non-metric skull variation in the red vole, and to test the hypothesis that such environmental conditions lead to an accumulation of changes at the level of non-metric traits.

\section{Materials and methods}

The study area was situated near Kamensk Ural'ski in the southeastern part of the Sverdlovsk region, Middle Urals, Russia. Trapping areas were characterized by similar climatic and habitat conditions and separated between $22 \mathrm{~km}$ and $30 \mathrm{~km}$ one from another (Fig. 1). Three areas were examined. The first was near Tygish Lake within the EURT boundaries, with an original level of contamination of about $5 \mathrm{c} / \mathrm{km}^{2}$. Further on it is referred to as the "affected population". Two control

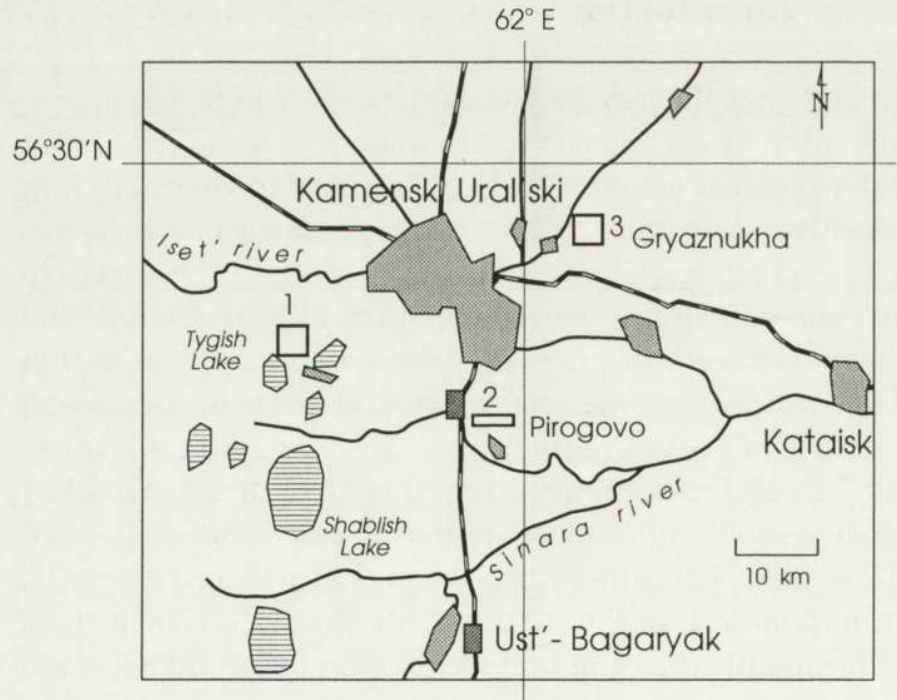

Fig. 1. Study areas (rectangles $1-3)$ in the Middle Urals near Kamensk Ural'ski. 
areas (Fig. 1: 2-3) were situated near the EURT (about 20-25 km apart), characerized by an original level of contamination of about $0.1 \mathrm{c} / \mathrm{km}^{2}$. One of them was located near the village Pirogovo, and the second one near the village Gryaznukha. The material was divided into 4 age classes according to the development of tooth roots and the form of the bottom part of the second upper molar (Tupikova et al. 1968): 1 - juveniles (up to 1 month old, not analyzed due to frequent damages on the skulls); 2 subadults (age approximately $1.5-2$ months); 3 - adults (age about $2.5-5$ months); 4 - senex (age higher than 8 months). The last age class consisted of the overwintering animals.

A total of 241 red vole skulls (age interval from 1.5 to 5 months: subadults and adults) were used for non-metric analyses. A total of 28 different ( 2 uni- and 26 bilateral) non-metric traits were scored using a binocular microscope (see Appendix, Fig. 2, and Vasilyev 1984). Each trait was scored on the left and the right side of the skull as "present" or "absent", and frequencies of occurrence for each trait were calculated on the basis of the total number of intact skull sides examined following Astaurov (1974) and Hartman (1980). Intercorrelations among traits were examined using Spearman rank correlation coefficients. Age (individuals of the current year vs overwintering ones) and sex dependence of character states were examined using cross-tabs and $G$-tests. Multiple comparisons across samples for particular traits were carried out by $G$-tests (Sokal and Rohlf 1981). The mean measure of divergence (MMD) between samples and the associated standard deviation (MSD) were calculated using the formula of C. A. B. Smith (Sjøvold 1977). The differences were considered statistically significant at $p=0.05$ if the MMD was twice as high as the MSD. In each sample, the measure of uniqueness (MU) was calculated as the sum of MMD's from all other samples (Berry 1964).

If the expression of a trait differed between both sides of the skull, asymmetry was recorded. The occurrence of directional asymmetry was examined by $\chi^{2}$-test. As an overall index for fluctuating asymmetry $\left(\mathrm{FA}_{\mathrm{nm}}\right)$ the proportion of bilateral traits asymmetric per individual was calculated following Markowski (1993). Differences in FAnm among samples were examined by Kruskal-Wallis test. Additionally Zhivotovskiïs index of intrapopulational diversity " $\mu$ " (the average number of character states per trait) was calculated (Zhivotovskii 1991). The statistic treatment of non-metric data was carried out using the programs ECOSTAT and PHEN (Version 2.1), developed by O. Zhigalskiï, O. Luk'yanov and A. G. Vasilyev, and by NTSYS-pc (Rohlf 1988).

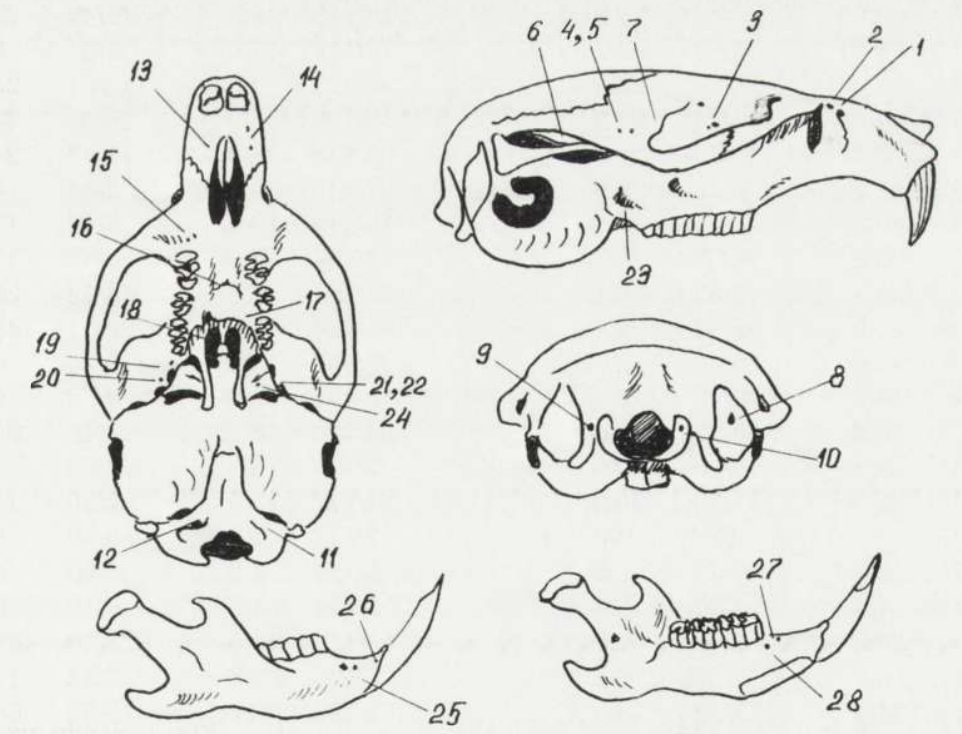

Fig. 2. Location of non-metric traits studied on the red vole skull. 1-28 - numbers of traits (see Appendix for their description). 


\section{Results}

Five non-metric traits $(8,11,12,15,17)$ showed age dependence (Table 1). For this reason all further analyses are based only on the samples of age classes 2

Table 1. Levels of significance for sex and age dependence of non-metric traits (G-test). ${ }^{*}-p<0.05$, ** $-p<0.01, * * *-p<0.001$. See Appendix for description of traits.

Number of non-metric trait

$\begin{array}{llllllllllllllllllllllllllll}1 & 2 & 3 & 4 & 5 & 6 & 7 & 8 & 9 & 10 & 11 & 12 & 13 & 14 & 15 & 16 & 17 & 18 & 19 & 20 & 21 & 22 & 23 & 24 & 25 & 26 & 27 & 28\end{array}$

Sex

Age

* $\quad *$

Table 2. Frequencies of non-metric skull traits in the affected and in control samples. $\mathrm{K}$ - the number of skull sides where a trait could be scored, $\mathrm{N}$ - the total number of skull sides examined. Gp pairwise comparison by $G$-test: ${ }^{*}-p<0.05$, $^{* *}-p<0.01$.

\begin{tabular}{|c|c|c|c|c|c|c|c|c|c|c|}
\hline \multirow{3}{*}{ Trait } & \multicolumn{5}{|c|}{ Affected (Tygish Lake) } & \multicolumn{5}{|c|}{ Control (Pirogovo) } \\
\hline & \multicolumn{2}{|c|}{1992} & \multicolumn{2}{|c|}{1993} & \multirow{2}{*}{ Gp } & \multicolumn{2}{|c|}{1992} & \multicolumn{2}{|c|}{1993} & \multirow{2}{*}{$\mathrm{Gp}$} \\
\hline & $\mathrm{K} / \mathrm{N}$ & $\%$ & $\mathrm{~K} / \mathrm{N}$ & $\%$ & & $\mathrm{~K} / \mathrm{N}$ & $\%$ & $\mathrm{~K} / \mathrm{N}$ & $\%$ & \\
\hline 1 & $4 / 90$ & 4.4 & $0 / 81$ & 0.0 & * & $8 / 124$ & 6.5 & $2 / 52$ & 3.8 & \\
\hline 2 & $12 / 45$ & 26.7 & $10 / 39$ & 25.6 & & $26 / 62$ & 41.9 & $9 / 26$ & 34.6 & \\
\hline 3 & $6 / 89$ & 6.7 & $5 / 82$ & 6.1 & & $7 / 122$ & 5.7 & $1 / 52$ & 1.9 & \\
\hline 4 & $0 / 90$ & 0.0 & $0 / 79$ & 0.0 & & $1 / 118$ & 0.9 & $0 / 50$ & 0.0 & \\
\hline 5 & $2 / 90$ & 2.2 & $1 / 79$ & 1.3 & & $2 / 118$ & 1.7 & $4 / 50$ & 8.0 & \\
\hline 6 & $9 / 90$ & 10.0 & $11 / 80$ & 13.8 & & $15 / 119$ & 12.6 & $11 / 47$ & 23.4 & \\
\hline 7 & $6 / 90$ & 6.7 & $5 / 80$ & 6.3 & & $13 / 118$ & 11.0 & $5 / 51$ & 9.8 & \\
\hline 8 & $17 / 89$ & 19.1 & $20 / 79$ & 25.3 & & $27 / 123$ & 22.0 & $12 / 51$ & 23.5 & \\
\hline 9 & $24 / 89$ & 27.0 & $21 / 77$ & 27.3 & & $42 / 120$ & 35.0 & $19 / 43$ & 44.2 & \\
\hline 10 & $25 / 89$ & 28.1 & $18 / 75$ & 24.0 & & $31 / 118$ & 26.3 & $11 / 45$ & 24.4 & \\
\hline 11 & $14 / 89$ & 15.7 & $6 / 75$ & 8.0 & & $27 / 118$ & 22.9 & $2 / 44$ & 4.5 & $* *$ \\
\hline 12 & $18 / 89$ & 20.2 & $26 / 75$ & 34.7 & * & $16 / 119$ & 13.4 & $6 / 44$ & 13.6 & \\
\hline 13 & $23 / 90$ & 25.6 & $24 / 82$ & 29.3 & & $7 / 124$ & 5.7 & $6 / 52$ & 11.5 & \\
\hline 14 & $10 / 90$ & 11.1 & $5 / 82$ & 6.1 & & $27 / 124$ & 21.8 & $14 / 52$ & 26.9 & \\
\hline 15 & $27 / 90$ & 30.0 & $26 / 82$ & 31.7 & & $54 / 124$ & 43.5 & $25 / 51$ & 49.0 & \\
\hline 16 & $7 / 45$ & 15.6 & $5 / 40$ & 12.5 & & $3 / 60$ & 5.0 & 0.26 & 0.0 & \\
\hline 17 & $13 / 89$ & 14.6 & $8 / 79$ & 10.1 & & $3 / 122$ & 2.5 & $3 / 50$ & 6.0 & \\
\hline 18 & $70 / 89$ & 78.7 & $54 / 80$ & 67.5 & & $68 / 120$ & 56.7 & $28 / 46$ & 60.9 & \\
\hline 19 & $8 / 90$ & 8.9 & $8 / 80$ & 10.0 & & $7 / 117$ & 6.0 & $2 / 50$ & 4.0 & \\
\hline 20 & $26 / 90$ & 28.9 & $21 / 80$ & 26.3 & & $21 / 117$ & 17.9 & $7 / 50$ & 14.0 & \\
\hline 21 & $1 / 90$ & 1.1 & $0 / 80$ & 0.0 & & $2 / 117$ & 1.7 & $0 / 50$ & 0.0 & \\
\hline 22 & $6 / 90$ & 6.7 & $6 / 80$ & 7.5 & & $5 / 117$ & 4.3 & $3 / 50$ & 6.0 & \\
\hline 23 & $4 / 90$ & 4.4 & $4 / 80$ & 5.0 & & $5 / 117$ & 4.3 & $0 / 49$ & 0.0 & \\
\hline 24 & $32 / 90$ & 35.6 & $38 / 80$ & 47.5 & & $53 / 119$ & 44.5 & $23 / 49$ & 46.9 & \\
\hline 25 & $6 / 89$ & 6.7 & $7 / 80$ & 8.8 & & $6 / 124$ & 4.8 & $7 / 52$ & 13.5 & \\
\hline 26 & $19 / 89$ & 21.3 & $11 / 79$ & 13.9 & & $31 / 123$ & 25.2 & $18 / 52$ & 34.6 & \\
\hline 27 & $16 / 89$ & 18.0 & $12 / 80$ & 15.0 & & $18 / 124$ & 14.5 & $7 / 52$ & 13.5 & \\
\hline 28 & $9 / 89$ & 10.1 & $8 / 80$ & 10.0 & & $22 / 124$ & 17.7 & $15 / 52$ & 28.8 & \\
\hline
\end{tabular}


Table 3. Frequencies of non-metric skull traits in the affected and in two control populations of the red vole (data from 1992 and 1993 pooled). $\mathrm{K}$ - the number of skull sides where a trait could be scored, $\mathrm{N}$ the total number of skull sides evaluated. Significance level: ${ }^{*}-p<0.05, * *-p<0.01,{ }^{* * *}-p<0.001$.

\begin{tabular}{|c|c|c|c|c|c|c|c|}
\hline \multirow{3}{*}{ Trait } & \multirow{2}{*}{\multicolumn{2}{|c|}{$\begin{array}{c}\text { Affected } \\
\text { Tygish Lake }\end{array}$}} & \multicolumn{4}{|c|}{ Control } & \multirow{3}{*}{$\begin{array}{c}\text { Multiple } \\
G \text {-test }\end{array}$} \\
\hline & & & \multicolumn{2}{|c|}{ Pirogovo } & \multicolumn{2}{|c|}{ Gryaznukha } & \\
\hline & $\mathrm{K} / \mathrm{N}$ & $\%$ & $\mathrm{~K} / \mathrm{N}$ & $\%$ & $\mathrm{~K} / \mathrm{N}$ & $\%$ & \\
\hline 1 & $4 / 171$ & 2.3 & $4 / 231$ & 1.7 & $1 / 78$ & 1.3 & \\
\hline 2 & 22.84 & 26.2 & $43 / 116$ & 37.1 & $16 / 39$ & 41.0 & \\
\hline 3 & $11 / 171$ & 6.4 & $10 / 229$ & 4.4 & $0 / 75$ & 0.0 & * \\
\hline 4 & $0 / 169$ & 0.0 & $1 / 221$ & 0.5 & $0 / 74$ & 0.0 & \\
\hline 5 & $3 / 169$ & 1.8 & $8 / 221$ & 3.6 & 0.74 & 0.0 & \\
\hline 6 & $20 / 170$ & 11.8 & $36 / 218$ & 16.5 & $18 / 74$ & 24.3 & \\
\hline 7 & $11 / 170$ & 6.5 & $25 / 220$ & 11.4 & $6 / 73$ & 8.2 & \\
\hline 8 & $37 / 168$ & 22.0 & $40 / 230$ & 17.4 & $14 / 76$ & 18.4 & \\
\hline 9 & $45 / 166$ & 27.1 & $70 / 218$ & 32.1 & $24 / 74$ & 31.1 & \\
\hline 10 & $43 / 164$ & 26.2 & $56 / 218$ & 25.7 & $15 / 74$ & 20.3 & \\
\hline 11 & $20 / 164$ & 12.2 & $48 / 218$ & 22.0 & $12 / 73$ & 16.4 & * \\
\hline 12 & $46 / 164$ & 28.0 & $27 / 219$ & 12.3 & $11 / 74$ & 14.9 & $* * *$ \\
\hline 13 & $47 / 172$ & 27.3 & $22 / 231$ & 9.5 & $13 / 78$ & 16.7 & $* * *$ \\
\hline 14 & $15 / 172$ & 8.7 & $46 / 231$ & 19.9 & $14 / 78$ & 17.9 & $* *$ \\
\hline 15 & $53 / 172$ & 30.8 & $101 / 231$ & 43.9 & $30 / 78$ & 38.5 & * \\
\hline 16 & $12 / 85$ & 14.1 & $3 / 113$ & 3.0 & $0 / 37$ & 0.0 & $* *$ \\
\hline 17 & $21 / 168$ & 12.5 & $14 / 224$ & 6.3 & $7 / 74$ & 9.5 & \\
\hline 18 & $124 / 169$ & 73.4 & $137 / 220$ & 62.3 & $43 / 73$ & 58.9 & * \\
\hline 19 & $16 / 170$ & 9.4 & $15 / 221$ & 6.8 & $11 / 70$ & 15.7 & \\
\hline 20 & $47 / 170$ & 27.6 & $28 / 221$ & 12.7 & $9 / 72$ & 12.5 & $* * *$ \\
\hline 21 & $1 / 170$ & 0.6 & $5 / 220$ & 2.3 & $2 / 72$ & 2.8 & \\
\hline 22 & $12 / 170$ & 7.1 & $11 / 220$ & 5.0 & $9 / 72$ & 12.5 & \\
\hline 23 & $8 / 170$ & 4.7 & $3 / 220$ & 1.4 & $1 / 73$ & 1.4 & \\
\hline 24 & $70 / 170$ & 41.2 & $90 / 222$ & 40.5 & $14 / 72$ & 19.4 & $* *$ \\
\hline 25 & $13 / 169$ & 7.7 & $20 / 232$ & 8.6 & $6 / 77$ & 7.8 & \\
\hline 26 & $30 / 168$ & 17.9 & $61 / 231$ & 26.4 & $24 / 77$ & 31.2 & * \\
\hline 27 & $28 / 169$ & 16.6 & $27 / 232$ & 11.6 & $11 / 77$ & 14.3 & \\
\hline 28 & $17 / 169$ & 10.1 & $42 / 232$ & 18.1 & $9 / 77$ & 11.7 & \\
\hline
\end{tabular}

and 3. Two traits $(10,17)$ showed a weak correlation with sex (Table 1$)$, but this was ignored because sexes were approximately equally distributed in all samples studied. The number of weak but statistically significant intercorrelations among traits did not exceed the random level of $5 \%$, and none of the traits was excluded from further analyses. There was no size dependence of the expression of non-metric traits, and no cases of directional asymmetry could be detected.

When frequencies of non-metric traits were compared between samples of the two successive years, there was a significant difference only for one trait in the control population (Pirogovo) and for two traits in the affected population (Tygish) 
Table 4. Matrices of MMD-distances between the affected and two control populations of the red vole in the years 1992 and 1993, for the pooled samples. Above the diagonal: MMD, below the diagonal: standard deviations (MSD). MU - measure of uniqueness. ns statistically not significant.

\begin{tabular}{lcccc}
\hline & \multicolumn{4}{c}{ Population } \\
\cline { 2 - 4 } & Tygish Lake (1) & Pirogovo (2) & Gryaznukha (3) & MU \\
\hline 1992 & & & \\
1 & - & 0.037 & 0.036 & 0.073 \\
2 & 0.006 & - & 0.012 (ns) & 0.049 \\
3 & 0.011 & 0.009 & - & 0.048 \\
1993 & & & & \\
1 & - & 0.055 & 0.056 & 0.111 \\
2 & 0.010 & - & 0.003 (ns) & 0.058 \\
3 & 0.012 & 0.015 & - & 0.059 \\
$1992+1993$ & & & & \\
For all traits & - & - & 0.045 & 0.085 \\
1 & - & 0.040 & 0.009 (ns) & 0.049 \\
2 & 0.003 & - & - & 0.054 \\
3 & 0.006 & 0.005 & - & 0.192 \\
Only for 11 traits which differed significantly among populations (see text) & \\
1 & - & 0.087 & 0.105 & 0.108 \\
2 & 0.005 & - & 0.021 & 0.126 \\
3 & 0.009 & 0.009 & - & \\
\hline
\end{tabular}

(Table 2). MMD-distances between samples of different years from one and the same site were very small and not significant both in Pirogovo (0.0097) and in the affected population $(-0.005)$. Therefore, the samples of different years were pooled for the further analyses. Samples from the affected and the two control populations differed significantly as to the frequencies of 11 non-metric traits (Table 3). Based

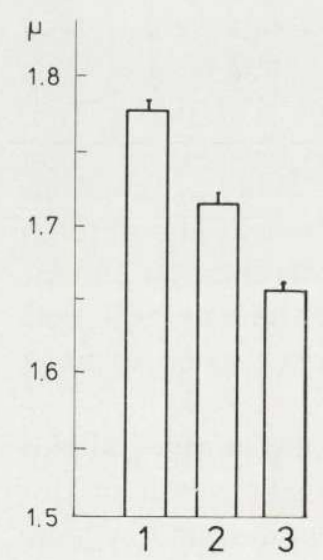

Fig. 3. Zhivotovskii's index of diversity $(\mu)$ for the affected and the control populations. 1 - Tygish Lake, 2 - Pirogovo, 3 - Grayaznukha. 
Table 5. Mean (SD) fluctuating asymmetry in the red vole Clethrionomys rutilus populations studied.

\begin{tabular}{ccc}
\hline & Population & \\
\hline Tygish Lake & Pirogovo & Gryaznukha \\
\hline$n=23$ & $n=37$ & $n=18$ \\
$20.6(1.5)$ & $22.0(1.0)$ & $20.3(2.0)$ \\
\hline
\end{tabular}

on all traits, MMD-distances between the affected and the two control populations were calculated (Table 4). MMD-distances between the affected and each of the control populations were statistically significant, but those among the control populations were not. Based only on the 11 significantly different traits shown in Table 3, the MMDs between the control populations were also significant (Table 4). The measure of uniqueness (MU) for the affected population was twice as high as in the control populations. Levels of intrapopulation diversity, based on Zhivotovskiï's index " $\mu$ ", are shown in Fig. 3 . They were higher in the affected population than in both control populations. There were no significant differences among populations as to levels of overall fluctuating asymmetry (Table 5).

\section{Discussion}

Monitoring of red vole populations using non-metric skull traits has revealed a higher level of intrapopulational diversity in the affected zone than in the control areas. The sample from the contaminated area was also shown to be the most separated one with respect to MMD-distances. These results remined stable even when samples from the respective years were treated separately (Table 4). Thus, as environmental conditions varied between the years of study, our results suggest changes in the genetic structure of the affected population to be responsible for the non-metric differentiation observed.

Non-metric traits are generally considered threshold traits, which means that they are under multifactorial genetic control (multiple genetic effects associated with the trait itself and additional genes responsible for the action of the threshold, see Berry and Searle 1963). According to Grüneberg (1955), non-metric variants are best regarded as the pleiotropic effects of slightly different normal alleles (isoalleles) of genes with major functions. Thus, the changes in frequencies of non-metric traits observed in the present study may be associated with genetic rearrangements related to the development of radioresistence in the affected red vole population (see also Il'enko and Krapivko 1993). For example, Grüneberg (1964) did not find any serious malformations in the skeletal structure of black rats Rattus rattus occupying an area with a relatively high natural level of radioactivity in southern India. In this case one may assume that the rat population inhabiting a radioactively contaminated area for some 600 years (about 
$800-1000$ generations) had resulted in an adaptive deviation from the initial genetic structure.

Examination of fluctuating asymmetry in non-metric traits did not reveal significant differences among the affected and the control populations, which may be interpreted in three different ways. First, although emphasized in a number of previous investigations (see Palmer and Strobeck 1986, Zakharov 1987, for reviews), fluctuating asymmetry may be no reliable indicator of environmental stress. Second, the permanent but low radioactive contamination in the affected area may be beyond the level of environmental stress usually being reflected by an increase of fluctuating asymmetry. Third, the affected population may have already adapted to low doses of radioactivity due to about 100 generations having elapsed since the Kyshtym accident. Further monitoring studies on the consequences of radionucleid contamination on the genetic structure of mammalian populations using non-metric traits are needed. Apart from their well documented function for detecting genomic and physiological stress (see eg Grüneberg 1955, Berry 1964 , Berry and Jakobson 1975, Zakharov 1987, Parsons 1992) it is an advantage of non-metric traits that they can be studied without costly laboratory equipment and are easily scored. In particular populations, though highly polluted at present, museum collections available from previous studies may serve as a reference for their genetic structure under more natural environmental conditions.

Acknowledgements: We thank Drs E. A. Gileva and E. A. Tarakhtii for allowing us to examine several specimens from their private collection. We thank our colleagues Dr O. A. Luk'yanov, Dr N. G. Evdokimov, K. I. Berdiugin, L. P. Sharova, V. P. Pozmogova, T. Yu. Surkova, T. L. Kardonina, and S. V. Muhacheva for their help in collecting material in the EURT zone. Dr V. S. Bezel commented on an earlier draft of this paper. This research was partly supported by a Russian fund for fundamental investigations: 93-04-6944, 93-04-6720, 93-04-12062 and Ecological Security of Russia grant 26/1.4.7.

\section{References}

Astaurov B. L. 1974. [Heredity and development]. Nauka, Moskva: 1-358. [In Russian]

Berry R. J. 1964. The evolution of an island population of the house mouse. Evolution 18: 468-483.

Berry R. J. and Jakobson M. E. 1975. Ecological genetics of an island population of the house mouse (Mus musculus). Journal of Zoology, London 175: 523-540.

Berry R. J. and Searle A. G. 1963. Epigenetic polymorphism of the rodent skeleton. Proceedings of the Zoological Society of London 140: 577-615.

Clarke G. M. 1992. Fluctuating asymmetry: a technique for measuring developmental stress of genetic and environmental origin. Acta Zoologica Fennica 191: 31-35.

Grüneberg H. 1955. Genetical studies on the skeleton of the mouse. XV. Relations between major and minor variants. Journal of Genetics 53: 515-535.

Grüneberg H. 1964. Genetical research in an area of high natural radioactivity in South India. Nature 204: $222-224$.

Hartman S. E. 1980. Geographic variation analysis of Dipodomys ordii using nonmetric cranial traits. Journal of Mammalogy 61: 436-448.

Il'enko A. I. 1974. [Radioizotopes concentration by animals and their influence on population]. Nauka, Moskva: 1-168. [In Russian] 
Il'enko A. I. and Krapivko T. P. 1993. [Ecological after-effects of radioactive contamination on populations of small mammals - strontiophores]. [In: Ecological after-effects of radioactive contamination at the South Urals. V. E. Sokolov and D. A. Krivolutcki, eds]. Nauka, Moskva: 171-180. [In Russian]

Markowski J. 1993. Fluctuating asymmetry as an indicator for differentiation among roe deer Capreolus capreolus populations. [In: Ecological genetics in mammals. G. B. Hartl and J. Markowski, eds]. Acta Theriologica 38, Suppl. 2: 19-31.

Palmer A. R. and Strobeck C. 1986. Fluctuating asymmetry: measurement, analysis, patterns. Annual Review of Ecology and Systematics 17: 391-421.

Parsons P. A. 1992. Fluctuating asymmetry: a biological monitor of environmental and genomic stress. Heredity 68: 361-364.

Rohlf F. J. 1988. NTSYS-pc; numerical taxonomy and system of multivariate statistical analyses programs (Version.1.1-1.40/440). Applied Biostatistics Inc., Deprtment of Ecology and Evolution, State University of New York. Exeter Publishing LTD, New York: 1-34.

Sjøvold T. 1977. Non-metrical divergence between skeletal populations. The theoretical foundation and biological importance of C. A. B. Smiths Mean Measure of Divergence. Ossa 4, Suppl. 1: 1-133.

Sokal R. R. and Rohlf F. J. 1981. Biometry. W. H. Freeman and Company, New York: 1-859.

Timofeeff-Ressovsky N. V., Jablokov A. V. and Glotov N. V. 1975. Grundris der Populationslehre. G. Fisher, Jena: 1-266.

Tupikova N. V., Sidorova G. A. and Konovalova E. A. 1968. A method of age determination in Clethrionomys. Acta Theriologica 13: 99-115.

Vasilyev A. G. 1984. [Izolation by distance and differentiation of populations]. Zhurnal obshchei biologii 45: 164-176. [In Russian]

Yablokov A. V. 1986. Population biology. Progress and problems of studies on natural populations. MIR Publishers, Moscow: 1-303.

Yushkov V. I., Trapeznikov A. V. and Molchanova I. V. 1993. [Radioecological studies of lakes' coastal zone on the EURT's territory in Sverdlovsk region]. [In: Realization of Russian Federation State Programme of radiation rehabilitation of the Ural region]. Ekaterinburg: 9-10. [In Russian]

Zakharov V. M. 1987. [Asymmetry of animals]. Nauka, Moskva: 1-216. [In Russian]

Zakharov V. M. and Clarke D. M. (eds). 1993. [Biotest. The integral estimation of the health of ecosystems and separate species]. Moscow Branch of International Found "Biotest", Moskva: 1-68. [In Russian]

Zhivotovskiï L. A. 1991. [Population biometry]. Nauka, Moskva: 1-271. [In Russian]

Received 7 August 1995, accepted 30 August 1995. 
APPENDIX. List of non-metric traits studied in the red vole skull. * - unilateral traits.

\begin{aligned} & \hline No \multicolumn{1}{c}{ Trait and its morphological expression } \\ & \hline 1. Preorbital foramen doubled. \\ & 2. Forma acuminata os nasale - the posterior margin of the nasal bone is convex. \\ & 3. Foramen ethmoidale doubled. \\ & 4. Foramen temporale absent. \\ & 5. Foramen temporale doubled. \\ & 6. Meatus temporale absent. \\ & 7. Foramen squamosum present. \\ & 8. Fenestra flocculi present. \\ & 9. Foramen occipitale single. \\ & 10. Internal condylar foramen present. \\ & 11. Internal foramen hypoglossi single. \\ & 12. Accessory internal foramen hypoglossi present. \\ & 13. Foramen praemaxillare absent. \\ & 14. Foramen praemaxillare doubled. \\ & 15. Maxillary foramen I doubled. \\ & *16. Fenestra palatinae present. \\ & 17. Posterior margin of palate is closed. \\ & 18. Foramen sphenoidale laterale present. \\ & 19. Accessory foramen rotundum present. \\ & 20. Accessory foramen ovale present. \\ & 21. Accessory longitudinal lamina of foramen ovale. \\ & 22. Accessory transversal lamina of foramen ovale. \\ & 23. Joining of foramen rotundum and foramen ovale. \\ & 24. Foramen on ventral surface of lateral lamina of processus pterygoideus present. \\ & 25. Mental foramen doubled. \\ & 26. Anterior accessory mental foramen present. \\ & 27. Supra-dentary foramen present. \\ & 28. Internal supra-dentary foramen present. \\ & \hline\end{aligned}

